\title{
Community Oriented Ectoparasite Intervention System: Concepts for On-Farm Application of Indigenous Veterinary Medication
}

\section{Ravikumar RK*, Periyaveeturaman C, Selvaraju D, Amol S Kinhekar, Lopamudra Dutta, VIPIN KUMAR}

\author{
National Innovation Foundation-India, Satellite Complex, Jodhpur Tekra, Premchand Nagar Road, Satellite, \\ Ahmedabad 380 015, Gujarat, India.
}

\begin{abstract}
An experimental research study enabled livestock owners to identify and express their immediate problem which was negatively affecting welfare of their livestock. Members of a village community in Gandhinagar district of Gujarat, India perceived ectoparasite infestation as a major problem in their livestock herds, which was generally not focussed upon by the stakeholders. Farming community looked for a change and keenly took up on-farm experimentation upon finding successful clinical evidence of the medication. A farmer assessment method was derived in consultation with research team as livestock owners had adequate knowledge of disease and welfare of animals. After noticing improvement in their animals they convened a meeting to share their findings. These feedbacks lead to continuation experimentation throughout the trial period of 21 days. The study showcased a method of mobilizing communities for health care intervention in livestock production system. This non-linear innovation system has provided necessary opportunity to the livestock farmers, to be a part of research system. This has led to desirable exchange of knowledge and derived benefit through implementation. Further, research has demonstrated an effective indigenous medication to overcome most resistant ectoparasite affecting livestock worldwide. The indigenous medication had significantly reduced tick infestation and protected the affected animals by minimizing skin lesions. During the 21-day observation period reoccurrence of tick infestation was not noticed. Sustainable agriculture and livestock productivity can be promoted through this environment friendly, cost-effective indigenous knowledge system. These measures of intervention have to be dovetailed into existing animal healthcare system catering to health care.
\end{abstract}

Keywords | Ectoparasite, Community, Indigenous, Sustainability, Innovation system

\footnotetext{
Editor Alok Sharma, Professor (VMI) \& Head, Dept. of Veterinary AH Extension Education, Dr. G. C. Negi College of Veterinary \& Animal Sciences, Palampur, Himachal Pradesh, India.

Special Issue | 1(2016) "Welfare issues, Environment, Societal learning and Innovation in Livestock Science"

Received | December 15, 2015; Revised | January 12, 2016; Accepted | January 13, 2016; Published | January 20, 2016

*Correspondence | Ravikumar RK, National Innovation Foundation-India, Satellite Complex, Jodhpur Tekra, Premchand Nagar Road, Satellite, Ahmedabad, Gujarat, India; Email: ravikumar@nifindia.org

Citation | Ravikumar RK*, Periyaveeturaman C, Selvaraju D, Kinhekar AS, Dutta L, Kumar V (2016). Community oriented ectoparasite intervention system: Concepts for on-farm application of indigenous veterinary medication. Adv. Anim. Vet. Sci. 4(1s): 9-19.

DOI | http://dx.doi.org/10.14737/journal.aavs/2016/4.1s.9.19

ISSN (Online) | 2307-8316; ISSN (Print) | 2309-3331
}

Copyright (c) 2016 Ravikumar et al. This is an open access article distributed under the Creative Commons Attribution License, which permits unrestricted use, distribution, and reproduction in any medium, provided the original work is properly cited.

\section{INTRODUCTION}

A nimal husbandry provides occupation and household nutrition throughout the year for rural households (Mondal et al., 2013). However, there are many factors that affect the farm animal welfare and productivity. Ectoparasite like ticks cause loss in productivity through tick worry, blood loss, hide damage, injection of toxins and transmission of diseases (Ducornez et al., 2005). Infestation with ectoparasites reduces economic gains and affects the welfare of farm animals (Alemu et al., 2014). Increased inci- dence of blood protozoan diseases is noticed where ticks act as intermediate hosts (Prakasan and Ramani, 2007). Control measures of tick infestation are difficult because ticks have a few natural predators (Ghosh et al., 2008) and quickly develop resistance to drugs (Itty et al., 1995; Castro-Janer et al., 2010; Mendes et al., 2011; Kumar et al., 2011). Poor disease surveillance and diagnosis, are impediments to livestock health (Devendra, 2002). These parasites were not studied sufficiently due to lack of urgency to understand tick borne diseases in animals (Chhillar et al., 2014; Geary and Thompson, 2003). 
The present livestock system is troubled with poor availability of medicines, techniques for assesing tick resistance, feedback loop for new drug development and industry response and sharing of scientific developments with farmers (FAO, 2004; Ravikumar and Chander, 2011). In terms of dairy farmer's perspective, their poor networking skills, physically demanding farming activities and time availability to seek alternative technologies pose distinct challenge (Kadivendi et al., 2015). There is increasing evidence that present strategies based on acaricides are not cost effective and have not produced a desired result (Frisch, 1999). National livestock intervention programs have to devise suitable measures to enhance the welfare of livestock. The need of farmers if not articulated, will not find any response from the organizations (Gupta, 1984). This reinforces magnitude of problem and identification of low cost sustainable technologies at dairy farmers premises. The present study was an attempt to showcase a methodology to sensitize community and to seek their support in control of ectoparasitic infestation with the help of indigenous knowledge system. The study has endeavoured to demonstrate a method to involve farming community in research system through environmental friendly technologies.

\section{PRE REQUISITE FOR INTEGRATED TICK CONTROL PROGRAM}

\section{Economic Importance, Public Health Hygiene and Non- Dramatic Nature}

As per 1997 estimates, the global annual production loss caused by tick-tick borne diseases (TTBDs) was to the tune of 18.70 billion US $\$$ and the market for acaricide was about US $\$ 500$ million per annum (Castro, 1997). Boophilus microplus, a hard tick resulted in average financial loss to the tune of US\$ 7.3 per animal per year, primarily due to production and cost of control (FAO, 2004). In India, the annual costs of TTBDs was found to be 384.30 US\$ million and 57.20 US\$ million due to T. annulata and Babesia sp. respectively. These vector-borne diseases cause prolonged illness and death of livestock if not treated properly. The loss due to direct effect of attachment ('tick-worry') was estimated at 57.2 US\$ million (Minjauw and Mcleod, 2003).

The use of synthetic acaricides has been a concern for quite sometime as these are known to cause undesirable effect on human health. The presence of fluzuron in calf passed via milk fat and withholding period of milk up to 30-40 days after treatment with avermectins are such examples (Frisch, 1999). Each tick sucks not less than 30 drops of blood to complete its life cycle (Mondal et al., 2013) affecting health of the animal. Dairy farmers fail to take any steps and incur production loss (Machila et al., 2007, Chhillar et al., 2014). Hence it is pertinent to identify different measures to complement veterinary institutional ef- fort for livestock welfare as well as for general public health (Patel et al., 2015).

\section{Farm Animal Welfare and Livestock}

\section{Production System in India}

Livestock welfare is human responsibility and ethically decided by social system involving veterinarian, affected animal and livestock owner (Odendaal, 1998). The unique nature of livestock production system needs to be appreciated as livestock owners seek different ways to address animal health (Dijkhuizen et al., 1995; Mcdermott et al., 1999). In countries like India the nature of small holder farming system makes it difficult for tick control or eradication (Tambi et al., 1999; Mondal et al., 2013).This is largely attributed to poor institutional mechanism in extending veterinary services by public sector (Ravikumar and $\mathrm{Ma}-$ hesh Chander, 2011). Livestock owners are distributed in wider geographical regions and effective services can only be promoted through ensuring availability of necessary resources in proximity.

Thus difficulty in accessing veterinary services and lack of availability of effective drugs (Turkson and Naandam, 2003) forces small holder farmers to look beyond the existing animal healthcare system. The current veterinary services were focussed to meet disease prevention such as vaccination and outbreaks. Studies had illustrated that indigenous system may fill the void by acting as technological alternatives that can provide innovative and sustainable solution at farmer's doorstep (Ravikumar et al., 2015). Acknowledging the knowledge outside conventional system means closed innovation era is over (Chesbrough, 2015). Exchange of knowledge by involving society provided rich incentives in managing innovation system. Involving farmers and to seek community animal health workers became necessity in smallholder farming system (Chatikobo et al., 2013). In this respect, community led tick control program needs to be envisaged wherein the livestock owners can identify their problem, look for alternatives and enhance the scope for improvised welfare.

\section{Participation of Communityand Demonstration of'TeCHNOLOGIES IN FARMER's Field FOR LiVESTOCK HeAlthCare}

Many developmental activities are carried out to support farming communities for their livelihood (Ravikumar et al., 2015a). Animal husbandry departments cater to health service for enhancing or sustaining productivity of livestock. Out of their many service delivery activities effective control of diseases and outbreaks are major responsibilities. However, disease control strategies, often fail to recognize constraints inherent among farmers, veterinary services, and other value chain actors (Rich and Perry, 2011). When technologies were more sustainable and provided substantial benefits for rural poor, promising advances in adoption 
of practices were noticed (Pretty et al., 2003). Norms of behaviour and trust are critical for understanding farmer's endorsement and response to information provided to them (Fisher, 2013; Mort et al., 2005).

There is always a pressing need for livestock owners to use desired technology immediately after problem identification. Technology adoption is not an isolated activity and it depends on a group or community activity. Further, identification of problem demands considerable time for discussion, individual or group meetings, formation and strengthening of network to nurture faith among stakeholders. Community frustration with programmes without providing 'hard' inputs is not unknown (Perry et al., 1984). Sustained benefit for livestock keepers can be achieved only through interactive participation and self-mobilisation (Catley and Leyland, 2001). In implementing such programs, stakeholders need to be readily available to work in tandem with livestock owners. Thus the level of involvement of farmers in decision-making process in planning as well as in implementation is the key to successful demonstration (Devendra, 2002; Holmes, 1997).

\section{Nature of Incidence, Resistance of Ticks and Technological Gap}

Asmaa et al. (2014) found highest incidence of tick infestation among cattle $(60.50 \%)$ followed by goat $(25.90 \%)$. Alemu et al. (2014) reported as high as 81.25 per cent incidence of tick infestation in cattle. The study by Prakasan and Ramani (2007) in South India reflected about 58.60 percent tick infestation. Treatment of hosts with acaricides to kill attached larvae, nymphs and adults has been widely practiced (Rajput et al., 2006). In 1980, resistance against amitraz was first reported in Boophilus microplus in Australia and its prevalent rate has been estimated at 10.00 percent (Jonsson and Hope, 2007). In six agro climatic regions of India, overall prevalence of synthetic pyrethriod (SP)-resistant Rhipicephalus (Boophilus.) microplus was found to be 66.60 percent (Sharma et al., 2012). These features indicated that over time, ticks had developed resistance to each group of acaricides (Frisch, 1999; Ghosh et al., 2008; Kiss et al., 2012).

Only limited research activities have been carried out to develop newer classes of acaricides as it is time consuming and expensive process (Graf et al., 2004). The competition between agrochemical companies for a share in ectoparasiticide market is intense and manifests in application of pressure on farmers to use chemicals (Castro, 1997). This causes long term negative environmental implications (Ghosh et al., 2008). Development of novel effective acaricidal compounds is essential to combat increasing resistance rates, concern for environment and food safety (Kiss et al., 2012; Galai et al., 2012; Rodriguez-Vivas et al., 2011; Beynon, 2012).
Geary and Thompson (2003) expressed that clinical situations like resistance factors of Boophilus have not been given due importance during technology development process. The parasite, Rhipicephalus microplus belongs to Ixodidae family of hard ticks and act as vector for protozoan diseases particularly Boophilus-Babesiosis-Cattle system. Ghosh et al. (2007) indicated that Rhipicephalus (Boophilus) microplus is the most prevalent cattle tick in various agro-climatic zones of India. This parasite is among the commercially important cattle ectoparasite in tropical and sub-tropical areas of the world (Klafke et al., (2006); Frisch, 1999). It has to be noted that $R$ (B.) microplus developed resistance to at least 43 chemicals and ranked sixth most resistant arthropod globally (Whalon et al., 2008). Farmers reported concern over reoccurrence of tick infestation after treatment with conventional medications (Kadivendi et al., 2015). Hence, identification and development of new means of acaricides have to be explored and this should happen without further damage to an environment increasingly harmed by existing agricultural practices (Pretty et al., 2003; Wood et al., 2000).

\section{Assessment of New Information Through On-} Farm Experimentation by Community

Many agricultural innovations if not most, were developed by farmers themselves (Roling, 1988). The systems with high level of social and human assets are more able to innovate in the face of uncertainty (UNEP, 2008; Pretty, 2008). In such situation, indigenous veterinary medications that are part of local knowledge system have to play greater role as they thrive over generation (Ravikumar et al., 2004). Treatment with herbal preparations is most common methods practiced by farmers (Regassa, 2000). This in itself is refreshing, as acaricide resistance for these indigenous medications have not been reported globally. Studies have been carried out to evaluate the role of plants in control of ticks under laboratory condition (Abdel-Shafy and Zayed (2002); Maciel et al., 2006) since 1950s, but their use as anti-tick material lie in the ethno-ecological practices of many traditional people (Kiss et al., 2012). Studies have demonstrated that indigenous medications can control hard ticks within 48 hours reflecting quicker and cost effective relief to animals (Ravikumar et al., 2015). However, there is limited evidence in reinforcing and strengthening indigenous systems through community mobilization (Ravikumar et al., 2015b). Attention on productive use of knowledge and skills of farmers to improve their self-reliance is required (Pretty, 2003). The need to listen to farming community, understand their innovative practices and to focus on development with human face have been illustrated (Devgania et al., 2015; Prasad, 2005).

Different studies have reported that livestock owners can provide valuable information on disease incidence and production losses (Perry et al., 1984; Catley and Mohammad, 
1996). In any disease, sick animals show certain abnormalities or clinical signs that farmers notice (Radostits et al., 2000). Farmers can use these clinical signs as a guide to identify type of the disease affecting their animal. Methods such as community education, livestock disease scoring systems were developed to plan veterinary intervention programs (Machila et al., 2007; Catley and Mohammed, 1996). This is important because improving disease management practices depend on individual actions of millions of rural families (Subedi and Garforth, 1996; Alex et al., 2002). Gupta (1995) opined that farmer's field should not be taken as knowledge receiving system; rather should complement knowledge generating system.

Most of the research work conducted in Southeast and South Asia is in experimental stations and lacks a farming systems approach (Devendra, 2002). In Indian context only 5.1 percent of farming community could access information on animal husbandry (Chander et al., 2010). It was amply illustrated that under smallholder production system location specific technologies need to be considered with support of livestock owners (Ravikumar et al., 2015a; Gaikwad et al., 2015). Hence, an alternative approach is needed wherein clients should themselves assess the technology for its wider adoption. This will help to minimize usage of products that do not have direct bearing at their farm steps. There is critical need for research and outreach for on-farm application of sustainable medications for organic livestock produce as well (Terrill et al., 2012). These features necessitate need to demonstrate importance of farmer assessment method(s) through on-farm trials. The present study therefore will help to understand and assimilate information about evaluation and adoption of indigenous veterinary knowledge among dairy farmers.

\section{RESEARCH METHODS}

\section{Study Area}

Three villages Amarapur, Aluva and Manekpur were randomly selected in the regions of Gandhinagar district, Gujarat State, India. Several interpersonal, group meetings were held among villagers during the months of August, September and October 2013 for identifying problems in rearing livestock. During these meetings, villagers expressed that ectoparasite infestation as major hurdle in animal productivity. In most farms in the study area, acaricides such as Cypermethrin, Flumethrin and Deltamethrin were used to control ticks and were found ineffective. A community led tick control program was therefore envisaged for controlling tick infestation through indigenous veterinary medication.

Establishment of Local Institutional SupporT In order to conduct on-farm experimentation, local in- stitutional support and farmer network were established through regular personnel contacts/dialogues. This was important to create opportune environment (Pretty et al., 2003) so as to understand and involve livestock owners. The village Amarapur was found suitable, as members of dairy co-operative society had volunteered for an interactive workshop. This led to sharing of information and enabled farmers to repose confidence on communicator(s) thereby choosing to accept and act on proposed solution.

\section{Research Design, Duration of Study and Sampling Procedure}

On-farm experimentation was planned as variables in field trials are stronger than those of laboratory experimentation (Kerlinger, 2004). Technical requirements, availability of resource person and experimental duration were taken into consideration while involving desired number of livestock owners. The study was carried out for a period of 21 days, which corresponds to life cycle of tick. A purposive non-probabilistic sampling procedure was chosen so as to select animals affected with ectoparasite infestation.

\section{OpPortunity FOR SHARING OF INFORMATION between Research Team and Farmers}

During the course of trial, two interactive meetings were conducted with farmers one before the start of experiment and the other on fourth day of the experiment. The second meeting was conducted to understand the efficacy of the medication as well as to have an opportunity for discussion during experimentation as information acquisition and translating information into knowledge are essential during implementation phase (Fisher, 2013).

\section{Examination, Selection Of Animals and} Efficacy Evaluation

Animals in the village were clinically examined for tick infestation at their premises through farm and home visits. During this phase it was taken into consideration that farmers were not asked to bring animals to a congregation point. The clinical observation over infested animals was carried out for two days in the entire village. The examination of animals was conducted in consultation with livestock owners so as to ensure broad uniformity of ectoparasite infestation among selected animals. Upon clinical examination, rate of infestation as decided and judged by the livestock owners was taken into account for selection of animals. Clinical conditions where there was no adequate infestation, were not considered. Observations were recorded on three point rating scale with score of 1 - Poor condition, 2 - Moderate condition and 3 - Good condition.

A total of 38 dairy animals infested with ectoparasite were randomly selected through Participant Observation Technique. The selected animals were maintained under nor- 
mal management conditions during the period of study. The observations of livestock owner participants were evaluated on Day 0 (before treatment) and on Day 7 (after treatment) as suggested by Vandermerve et al. (2005). The data were recorded, scored and suitably analysed. In order to overcome extraneous differences between groups, two related samples were taken for evaluation of efficacy. Each animal acted as its own control and was assessed by same livestock owner. Wilcoxon signed rank test was used to evaluate the efficacy of medication, thereby determining the direction of differences within the pair as well as the relative magnitude. The scores were statistically analysed and test statistic $z$ was calculated for large sample as per Siegel and Castellan (1988). In this experimental analysis, direction of difference is predicted, hence the region of rejection is one tailed. The table $\mathrm{p}$ value of test statistic $\mathrm{z}(\alpha=.01, z=0.1)$ was 0.45 and observed $p$ value for test statistic ( $z$ ) less than 0.45 or approaching zero indicated regions of rejection.

\section{Confirmatory Diagnosis of Ectoparasite}

Ticks were collected from affected animals for confirmatory diagnosis during clinical examination. The tick population was identified and found to be Rhipicephalus (Boophilus) microplus and Hyalomma spp., Thus it was confirmed that experimental animal population were infested with mixed tick population.

\section{Administration of Indigenous Medication for Control of Ticks}

Different age group of both cattle and buffaloes were considered for On-farm experimentation. Livestock owners were provided with indigenous veterinary medication for ectoparasite control. The dosage and method of administration were demonstrated to them. The indigenous ectoparasite medication was topically applied once daily for two days as described by traditional livestock healer Shri Periyaveeturaman (Periyaveeturaman et al., 2015). The duration between two treatments was 24 hours. Animals were observed on $0,1,2,7,13$ and 21 days post-treatment for detachment of ticks, re-infestation, skin damage, appetite and any other untoward reactions. Specific observations were noted with the help of livestock owners on $7^{\text {th }}$ day for rate of tick infestation, and $21^{\text {st }}$ day for observing impact of test medication.

\section{EXPERIMENTAL RESULTS}

\section{Effect of Indigenous Veterinary Medications Over Hard Tick InfESTATION}

A total of 38 samples were analysed statistically using Wilcoxon sign rank test to understand the efficacy of indigenous medications for control/containment of tick infestation.
This is a powerful non-parametric statistical test as it gives more weight to pair showing greater difference between "before and after treatment" conditions. The study evaluated ' $d i$ ' which is the difference of score for matched pair. The ranking of each of the observations was held by assigning rank one to smallest ' $d i$ ' without regard to sign. Subsequently signs were assigned to indicate ranks from negative or positive ' $d i$. The average of the rank was assigned for tied observation. The scoring pattern was based on elimination or reduction in ectoparasite and ability to protect animals from them.

It was found that in 14 animals, livestock owners did not observe changes after application of medication. In the remaining 24 clinical $(n=24)$ there was a change in scoring pattern as treatment resulted in variation of clinical signs. The sum of ranks of subjects whose $d$ s were in the direction predicted under $H_{1}\left(\mathrm{~T}^{+}=300\right)$ is presented in Table 1 . The value of $z$ as extreme is +3.11 have one tailed probability associated with occurrence when $H_{0}$ is true of 0.0009 ( $p$ value). The table $p$ value of $z(\alpha=.01, z=4.28)$ was too small, approaching zero. It is less than the table $p$ value of $\mathrm{z}(\alpha=.01, z=0.1)$, which was 0.45 , and in the regions of rejection. The results conclude that indigenous medication has significant effect in reduction of tick infestation.

\section{Clinical impact of Indigenous Medications Over Different Types of Skin Lesions}

Ectoparasites are major causative agents for skin lesions in livestock such as allergic reactions and nodulations. The control program should aim not only to reduce tick burden, but also reduce skin lesions (Chanieet al., 2010). The skin damage was codified through visual inspection by livestock owners in terms of swelling (inflammation) and nodule formation. The sum of ranks of subjects whose difference of score $(d s)$ were in the direction predicted under $H_{1}\left(\mathrm{~T}^{+}=278\right)$ is presented in Table 2 . The value of $z$ as extreme is +3.11 have one tailed probability associated with occurrence when $H_{0}$ is true of 0.0009 ( $p$ value). The table $p$ value of $z(\alpha=.01, z=3.65)$ was too small and in the regions of rejection. The study found that medication had significant effect in reducing skin lesions due to ectoparasite infestation. Further, the efficacy was also noticed over tick infested animals of different age groups.

\section{RESUlts of ON-FARM EXPERIMENTATION}

The study confirmed efficacy of indigenous medication on mixed tick infestation of Boophilus microplus and Hyalomma spp. in clinical situation. Observations over a period of 21 days did not show any re-occurrence of tick infestation. Implications of these findings are important for tick control measures not only in study locale but elsewhere as well. 
Table 1: Effect of indigenous veterinary medication against ectoparasite infestation*

\begin{tabular}{|c|c|c|c|c|c|}
\hline \multirow[t]{2}{*}{ 急 } & \multirow[t]{2}{*}{$\begin{array}{l}\text { Name of cattle owner and animal description } \\
\text { (Species, Age) }\end{array}$} & \multicolumn{2}{|c|}{$\begin{array}{l}\text { Score on three point scale } \\
\text { (efficacy of indigenous medication against mixed } \\
\text { population of Boophilus microplus and Hyalomma } \\
\text { spp.) }\end{array}$} & \multirow[t]{2}{*}{ di } & \multirow[t]{2}{*}{ Rank } \\
\hline & & Before (0 day) & After ( $7^{\text {th }}$ day) & & \\
\hline 1 & JeevanjiDajiyajiRathod/Crossbred Calf/3 months old & 1 & 3 & 2 & +13.5 \\
\hline 2 & RamajiDajiyajiRathod/Crossbred Cow/7 years & 1 & 2 & 1 & +1.5 \\
\hline 3 & RamajiDajiyajiRathod/Crossbred Calf/4 months & 1 & 2 & 1 & +1.5 \\
\hline 4 & LalshiShankarshiRathod/ Cross bred Cow/10 years & 1 & 3 & 2 & +13.5 \\
\hline 5 & LalshiShankarshiRathod/Buffalo /5 years & 1 & 3 & 2 & +13.5 \\
\hline 6 & LalshiShankarshiRathod/Buffalo /6 years & 1 & 3 & 2 & +13.5 \\
\hline 7 & LalshiShankarshiRathod/Crossbred Cow/10 years & 1 & 3 & 2 & +13.5 \\
\hline 8 & DasharathbhaiRatanbhaiRathod/cattle heifer/3 years & 1 & 3 & 2 & +13.5 \\
\hline 9 & DasharathbhaiRatanbhaiRathod/cattle heifer/2.5 years & 1 & 3 & 2 & +13.5 \\
\hline 10 & MukeshbhaiChavan/Crossbred Cow/4 years & 1 & 3 & 2 & +13.5 \\
\hline 11 & SurendrashiRathod/Buffalo/6 years & 1 & 3 & 2 & +13.5 \\
\hline 12 & SurendrashiRathod/Buffalo & 1 & 3 & 2 & +13.5 \\
\hline 13 & SurendrashiRathod/Buffalo & 1 & 3 & 2 & +13.5 \\
\hline 14 & SurendrashiRathod/Buffalo & 1 & 3 & 2 & +13.5 \\
\hline 15 & NagasinghGabajiRathod/ Crossbred Cow/7 years & 1 & 3 & 2 & +13.5 \\
\hline 16 & NagasinghGabajiRathod/ Crossbred Cow/4 years & 1 & 3 & 2 & +13.5 \\
\hline 17 & GhanshyamjiShankarshiRathod/indigenouscow/8 years & 1 & 3 & 2 & +13.5 \\
\hline 18 & RaghujiShankarshiRathod/Buffalo/3 years & 1 & 3 & 2 & +13.5 \\
\hline 19 & JaswantshiShankarshiRathod/Buffalo/4 years & 1 & 3 & 2 & +13.5 \\
\hline 20 & JaswantshishankarshiRathod/crossbred cow/5 years & 1 & 3 & 2 & +13.5 \\
\hline 21 & Nagasingh Gabaji Rathod/ Crossbred Cow/5 years & 1 & 3 & 2 & +13.5 \\
\hline 22 & RatanshiTakujiRathod/Crossbred Cow/5 years & 1 & 3 & 2 & +13.5 \\
\hline 23 & KanujiTakujiRathod/Buffalo/8 years & 1 & 3 & 2 & +13.5 \\
\hline 24 & KanujiTakujiRathod/Buffalo/7 years & 1 & 3 & 2 & +13.5 \\
\hline
\end{tabular}

${ }^{*} \mathrm{~N}=24 ; \mathrm{T}+=300 ; \mathrm{T}-=0 ; \mathbf{z}=4.28$

DISCUSSION, MEASUREMENT OF INTERVENTION IN CONTROL TO TICK INFESTATIONS

Filling the Void of Technological Alternatives, People's Unrest and Desire for New Challenge

The need for technologies depends upon nature of economic, environmental impact and production system. Livestock owners were aware of their management practices and technological requirements were prioritized as per their choice. Tick control was found to be most immediate necessity and community was geared to overcome the challenge. The interactive meeting before and after intervention, regular personnel interaction(s) during trial period enabled them to choose alternative technology as per their requirement. Each member had visualized prob- lem and voluntarily participated in experimentation so as to observe clinical welfare on their animals. The study had demonstrated a solution to an immediate societal problem where livestock owners were part of research system. This is in accordance with formal requirement of ensuring participation of individuals through regular discussion (Albrecht et al., 1989). The involvement of farming community in evaluation of affordable technologies illustrates an example of nonlinear innovation model.

\section{Evidence FOR DeVelopment of Farmer's} Assessment Methods

The relative merits of farmer participatory versus more technical approaches for livestock health care intervention were discussed globally. However, there needs to be systematic field work to augment these broad characterizations (De Leeuwet al., 1995). Maiti et al., (2013) referred 
Table 2: Effect of indigenous veterinary medication against ectoparasite infestation*

\begin{tabular}{|c|c|c|c|c|c|c|}
\hline us & $\begin{array}{l}\text { Name of cattle owner and animal } \\
\text { description (Species, Age) }\end{array}$ & $\begin{array}{l}\text { Ectoparasite location site } \\
\text { on animal }\end{array}$ & $\begin{array}{l}\text { Skin condition } \\
\text { croplus and } H y\end{array}$ & $\begin{array}{l}\text { o Boophilus mi- } \\
\text { a spp. infestation }\end{array}$ & di & Rank \\
\hline & & & Before (0 day) & After (21 $1^{\text {st }}$ day) & & \\
\hline 1 & $\begin{array}{l}\text { JeevanjiDajiyajiRathod/Crossbred } \\
\text { Calf/3 months old }\end{array}$ & Inguinal, Neck & S & 0 & 1 & +10 \\
\hline 2 & $\begin{array}{l}\text { RamajiDajiyajiRathod/Crossbred } \\
\text { Cow/7 years }\end{array}$ & Neck & S & 0 & 1 & +10 \\
\hline 3 & $\begin{array}{l}\text { RamajiDajiyajiRathod/Crossbred } \\
\text { Calf/4 months }\end{array}$ & Inguinal, Neck & $\mathrm{S}, \mathrm{N}$ & 0 & 2 & +22 \\
\hline 4 & $\begin{array}{l}\text { LalshiShankarshiRathod/ Cross bred } \\
\text { Cow/10 years }\end{array}$ & Neck & S & 0 & 1 & +10 \\
\hline 5 & $\begin{array}{l}\text { LalshiShankarshiRathod/Buffalo } / 5 \\
\text { years }\end{array}$ & Inguinal & S & 0 & 1 & +10 \\
\hline 6 & $\begin{array}{l}\text { LalshiShankarshiRathod/Buffalo / } 6 \\
\text { years }\end{array}$ & Neck & S & 0 & 1 & +10 \\
\hline 7 & $\begin{array}{l}\text { LalshiShankarshiRathod/Crossbred } \\
\text { Cow/10 years }\end{array}$ & Neck & S & $\mathrm{S}, \mathrm{N}$ & -2 & -22 \\
\hline 8 & $\begin{array}{l}\text { DasharathbhaiRatanbhaiRathod/ } \\
\text { cattle heifer/3 years }\end{array}$ & Neck & S & 0 & 1 & +10 \\
\hline 9 & $\begin{array}{l}\text { DasharathbhaiRatanbhaiRathod/ } \\
\text { cattle heifer/ } 2.5 \text { years }\end{array}$ & All over body & S & 0 & 1 & +10 \\
\hline 10 & $\begin{array}{l}\text { MukeshbhaiChavan/Crossbred } \\
\text { Cow/4 years }\end{array}$ & Neck & S & 0 & 1 & +10 \\
\hline 11 & SurendrashiRathod/Buffalo/6 years & Inguinal, Mammary gland & S & 0 & 1 & +10 \\
\hline 12 & SurendrashiRathod/Buffalo & Inguinal & S & 0 & 1 & +10 \\
\hline 13 & SurendrashiRathod/Buffalo & Inguinal & $\mathrm{N}$ & 0 & 1 & +10 \\
\hline 14 & SurendrashiRathod/Buffalo & Inguinal & $\mathrm{N}$ & 0 & 1 & +10 \\
\hline 15 & $\begin{array}{l}\text { NagasinghGabajiRathod/ Crossbred } \\
\text { Cow/7 years }\end{array}$ & Neck & $\mathrm{S}, \mathrm{N}$ & 0 & 2 & +22 \\
\hline 16 & $\begin{array}{l}\text { NagasinghGabajiRathod/ Crossbred } \\
\text { Cow/4 years }\end{array}$ & Neck & S & 0 & 1 & +10 \\
\hline 17 & $\begin{array}{l}\text { GhanshyamjiShankarshiRathod/ } \\
\text { indigenous cow/8 years }\end{array}$ & Neck & S & 0 & 1 & +10 \\
\hline 18 & $\begin{array}{l}\text { RaghujiShankarshiRathod/ Buffa- } \\
\text { lo/3 years }\end{array}$ & Inguinal & S & 0 & 1 & +10 \\
\hline 19 & $\begin{array}{l}\text { JaswantshiShankarshiRathod/Buffa- } \\
\text { lo/4 years }\end{array}$ & Neck & S & 0 & 1 & +10 \\
\hline 20 & $\begin{array}{l}\text { JaswantshishankarshiRathod/cross- } \\
\text { bred cow/5 years }\end{array}$ & Neck & S & 0 & 1 & +10 \\
\hline 21 & $\begin{array}{l}\text { Nagasingh Gabaji Rathod/ Cross- } \\
\text { bred Cow/5 years }\end{array}$ & Inguinal, Neck & S & 0 & 1 & +10 \\
\hline 22 & $\begin{array}{l}\text { RatanshiTakujiRathod/Crossbred } \\
\text { Cow/5 years }\end{array}$ & Neck & $\mathrm{S}, \mathrm{N}$ & 0 & 2 & +22 \\
\hline 23 & KanujiTakujiRathod/Buffalo/8 years & Inguinal & $\mathrm{S}, \mathrm{N}$ & 0 & 2 & +22 \\
\hline 24 & KanujiTakujiRathod/Buffalo/7 years & Inguinal & S & 0 & 1 & +10 \\
\hline
\end{tabular}

${ }^{*} \mathrm{~N}=24 ; \mathrm{S}=$ Swelling (Inflamed); $\mathbf{N}=$ Nodule; $\mathrm{T}+=278 ; \mathrm{T}-=22 ; \mathbf{z}=3.65$

that farming community has been doing informal experiments. Veterinarians value these pastoralist knowledge and skill towards animal-health concerns and diagnosis of ailments (Catley and Leyland, 2001). Livestock owners had ability to differentiate disease condition, as they have more empathy towards their animal and see themselves responsible for welfare (Odendaal, 1998). The purpose of this study was to understand monitoring methods where eval- 
uation criteria were set by livestock owners in discussion with veterinary professionals.

Meeting livestock owners in their dairy society and immediate visit to clinically observe their affected animals had desired effect in reinforcing their positive behaviour. Each of these animals was observed clinically for at least 30 minutes. This had resulted in development of three point rating scale using participant observation technique. Farmers owing to visible impact of medications that was easy to administer sustained the length of time required for experimentation. Thus evaluation method, medication available with them (hard inputs) and nature of observant technique based on their wisdom may help in situation wherein limited government veterinary facilities or record keeping activities are involved.

\section{ERAdication OF Ticks and Impact ON}

\section{EnVironment, An Illustrated Model}

In most intervention programs, access to acaricides, knowledge about vaccine, resource personnel ability to administer vaccine, drug, monitoring agency for control of disease outbreaks were presumed to be available. However, prevailing situation among pastoralists and surrounding infrastructure facilities were not up to such expectations. The price of an individual vaccination can range from US $\$ 3.30$ to US $\$ 12.60$ indicating available solutions were expensive, unsuitable for distribution and difficult to access (Minjauw and Mcleod, 2003). Studies had confirmed that control program for ticks had limitation when it involves large number of livestock (Bowman, 2006; Jongejan and Uilenberg, 1994). The strength of local community who has been rearing livestock was not taken into consideration in intervention program. It is established fact that no particular public-private partnership can cater to all animal health inputs (Swallow et al., 1995). In this context, integrated control of ticks through indigenous medicinal system is paramount. The study had revealed that hard ticks that were not responding to conventional acaricides were controlled by indigenous medications. Hence, attention is needed to replicate such illustrated model of participatory technology development and to identify suitable methodologies to disseminate these cost effective solutions. Evaluation of these approaches enables practitioners to understand and cultivate necessary skills towards implementing intervention program with people. This will help to enrich knowledge in executing indigenous medications for betterment of welfare of livestock and ease in developing suitable framework.

\section{Scaling up through Appropriate Policies}

Developmental policies and research priorities were directed towards livestock disease outbreaks that were well articulated. The study reported that animal welfare is affected by issues such as ectoparasite infestation that needs imme- diate attention. Effective linkages with communities along with proper feedback mechanism are prerequisite for such issues to emerge in mainstream activities. The medicines that were working elsewhere did not have much impact in local situation hence support system needs to overcome such challenges in smallholder livestock production system. Research system has to assist livestock owners who were seeking alternative solutions and utilize their knowledge by adopting suitable approaches. The study illustrated that when livestock owners understand the problem, training took backseat and mobilization of community become forefront. Hence, motivation of communities in terms of sharing their time and resources are relevant. This helps planners to devise strategies and for effective implementation of intervention activities. Research system, particularly formal institutions should contribute to diffusion of knowledge and develop overall welfare standards in rural society.

\section{CONCLUSION(S)}

We have observed that many livestock intervention programs begin at laboratory and view clientele primarily as receiver. Accordingly, most of the National Development Programs were devised for large-scale dissemination activities and miss the true nature of imminent problem facing community. Through the present study, it was amply demonstrated that conventional ectoparacitiside that were held as scientific package of practices were not effective. Development of resistance, lack of attention to less dramatic ailments, prevalence or reoccurrence of tick population and environmental damage were discussed. Development of vaccine against tick population is also in the pipeline and mixed reaction have been received while promoting them under field conditions. The prevailing situation is found not only in India, but throughout world. Hence, measures to control ectoparasite infestation surely calls for solutions which are cost effective, have lesser implications to environment, better adopted and known to farming community.

The study had examined impact beyond technological intervention and illustrated exciting features for intervention in community. The need to gain trust and setting up of social assets among villagers is functional responsibility before taking any pragmatic approach. The goodwill generated through such measures in turn reflected in community participation. Natural resistance of community was found to be dismal and led usage of technology in lesser duration of time. Thus, different national systems need to rethink on these lines for designing development program involving livestock. The study is one such example to illustrate farmer led innovation-intervention program is here to stay as an alternative option. 


\section{ACKNOWLEDGEMENTS}

The authors acknowledge livestock owners who had volunteered their animals and Department of Veterinary Parasitology, Nagpur Veterinary College, Nagpur for identifying ectoparasite.

\section{AUTHOR'S CONTRIBUTION}

All authors contributed equally to the manuscript.

\section{CONFLICT OF INTEREST}

Authors declare that they have no conflict of interest.

\section{REFERENCES}

-Abdel -Shafy S, Zayed AA (2002). In vitro acaricidal effect of plant extract of neem seed oil (Azadirachta indica) on egg, immature, and adult stages of Hyalomma anatolicum excavatum (Ixodoidea: Ixodidae). Vet. Parasitol. 106: 89-96. http://dx.doi.org/10.1016/S0304-4017(02)00023-7

-Albrecht H, Bergmann H, Diederich G, Grober E, Hoffmann V, Keller P, Payr G, Sulzer R (1989). Rural Development Series, Agricultural Extension, Volume 1: Basic concepts and methods, Technical Cooperation- Federal Republic of Germany, Technical Centre for Agricultural and Rural Cooperation, Wageningen. Revised Special edition, New Age International (P) Limited, New Delhi. Pp. 41-54.

-Alemu G, Chanie M, Mengesha D, Bogale, B (2014). Prevalence of ixodid ticks on cattle in Northwest Ethipia. Acta Parasitologica Globalis. 5(2): 139-145.

-Alex G, Zijp W, Byerlee D (2002). Rural extension and advisory services: New directions. Rural Strategy Background Paper, No. 9.AKIS Thematic Team, World Bank, Washington, DC. <http://info.worldbank.org/etools/docs/library/51025/ ZipAgExtension1/ag_extension1/Materials/additional/ Rural_extension.pdf> cited on 27.05.2014

-Asmaa NM, Elbably MA, Shokier KA (2014). Studies on prevalence, risk indicators and control options for tick infestations in ruminants. Beni-Suef University J. Basic Appl. Sci. 3: 68-73.

-Beynon SA (2012). Potential environmental consequences of administration of ectoparasiticides to sheep. Vet. Parasitol. 189: 125- 135. http://dx.doi.org/10.1016/j. vetpar.2012.03.040

-Bowman DD (2006). Successful and currently ongoing parasitic eradication programs. Vet. Parasitol. 139: 293-307. http:// dx.doi.org/10.1016/j.vetpar.2006.04.020

- Castro JJ (1997). Sustainable tick and tickborne disease control in livestock improvement in developing countries. Vet. Parasitol. 71: 77-97. http://dx.doi.org/10.1016/S03044017(97)00033-2

- Castro-Janer, E Martins JR, Mendes MC, Namindome A, Klafke GM, Schumaker TTS (2010). Diagnoses of fipronil resistance in Brazilian cattle ticks (Rhipicephalus (Boophilus) microplus) using in vitro larval bioassays. Vet. Parasitol. 173: 300-306. http://dx.doi.org/10.1016/j.vetpar.2010.06.036

- Catley A, Leyland T (2001). Community participation and the delivery of veterinary services in Africa. Prevent. Vet.
Med. 49: 95-113. http://dx.doi.org/10.1016/S01675877(01)00171-4

- Catley AP, Mohammed AA (1996). The use of livestockdisease scoring by a primary animal-health project in Somaliland. Prevent. Vet. Med. 28: 175- 186. http://dx.doi. org/10.1016/0167-5877(96)01038-0

- Chander M, Dutt T, Ravikumar RK, Subrahmanyeswari, B (2010). Livestock technology transfer service in India: A review. Indian J. Anim. Sci. 80 (11): 1115-25.

- Chanie M, Negast T, Sirak, A (2010). Ectoparasites are the major causes of various types of skin lesions in small ruminants in Ethiopia. Trop. Anim. Health Prod. 42 (6): 1103-9. http:// dx.doi.org/10.1007/s11250-010-9531-4

- Chatikobo P, Choga T, Ncube C, Mutambara J (2013). Participatory diagnosis and prioritization of constraints to cattle production in some smallholder farming areas of Zimbabwe. Prevent. Vet. Med. 109: 327-333. http://dx.doi. org/10.1016/j.prevetmed.2012.10.013

- Chesbrough H (2015). From Open Science to Open Innovation, Institute for Innovation and Knowledge Management, Science Business Publishing, UC Berkeley.

- Chhillar S, Chhilar JS, Kaur H (2014). Investigations on some Hard ticks (Acari: Ixodidae) infesting domestic buffalo and cattle from Haryana, India. J. Entomol. Zool. Stud. 2(4): 99-104.

-Devendra C (2002). Crop-animal systems in Asia: Implications for research. Agri. Syst. 71: 169-177. http://dx.doi. org/10.1016/S0308-521X(01)00034-8

-Devgania BS, Khordia D, Chodvadiya MB, Patel R, Patel D, Kinhekar AS, Singh PK, Kumar V, Bhojne GR, Ravikumar RK, Kumar V (2015). Reverence of community towards grassroot livestock innovation: Responding to stakeholders need against sub-clinical mastitis in Amreli District, Gujarat, India. Adv. Anim. Vet. Sci. 3(12): 689-693. http:// dx.doi.org/10.14737/journal.aavs/2015/3.12.689.693

-De Leeuw PN, Mcdermott JJ, Lebbie SHB (1995). Monitoring of livestock health and production in sub Saharan Africa. Prevent. Vet. Med. 25: 195-212. http://dx.doi. org/10.1016/0167-5877(95)00547-1

-Dijkhuizen AA, Huirne RBM, Jalvingh AW (1995). Economic analysis of animal diseases and their control. Prevent. Vet. Med. 25: 135-149. http://dx.doi.org/10.1016/01675877(95)00535-8

-Ducornez S, Barré N, Miller RJ, deGarine-Wichatisky M (2005). Diagnosisofamitraz resistance in Boophilus microplus in New Caledoniawith modified larval packet test. Vet. Parasitol. 130: 285-292. http://dx.doi.org/10.1016/j. vetpar.2005.04.018

-FAO (2004). Guidelines resistance management and integrated parasite control in ruminants. Module 1. Ticks: Acaricide resistance: Diagnosis, management and prevention. Food and Agriculture Organization of the United Nations, Rome. <ftp://ftp.fao.org/docrep/fao/010/ag014e/ag014e05.pdf> Cited on 23.01.14.

- Fisher R (2013). A gentleman's handshake: The role of social capital and trust in transforming information into usable knowledge. J. Rural Stud. 31: 13-22. http://dx.doi. org/10.1016/j.jrurstud.2013.02.006

-Frisch JE (1999). Towards a permanent solution for controlling cattle ticks. Int. J. Parasitol. 29:57-71. http://dx.doi. org/10.1016/S0020-7519(98)00177-5

-Gaikwad SLR, Ramana DN, Solanki RP, Khatana LB, Gohil NK, Vasav NG, Patel P, Sahay NS, Patel J, Ravikumar RK, 
Singh PK, Kinhekar AS, Kumar V (2015). Efficacy of an indigenous veterinary medication to control endoparasite infestation in clinically diagnosed large ruminants affected with diarrhoea amongst field conditions: Gujarat, India. Euro. J. Exp. Biol. 5(5): 81-84.

- Galai Y, Canales M, Saïd MB, Gharbi M, Mhadhbia M, Jedidi M, Fuente J,Darghouth MA (2012). Efficacy of Hyalomma scupense (Hd86) antigen against Hyalomma excavatum and H. scupense tick infestations in cattle. Vaccine 30: 70847089. http://dx.doi.org/10.1016/j.vaccine.2012.09.051

- Geary TG, Thompson DP (2003). Development of antiparasitic drugs in the $21^{\text {st }}$ century. Vet. Parasitol. 115:167-184. http:// dx.doi.org/10.1016/S0304-4017(03)00205-X

- Ghosh S, Bansal GC, Gupta SC, Ray DD, Khan MQ, Irshad H,Shahiduzzaman M, Seitzer U, Ahmed JS (2007). Status of tick distribution in Bangladesh, India and Pakistan. Parasitol. Res. 101(Suppl.2): 207-216. http://dx.doi. org/10.1007/s00436-007-0684-7

- Ghosh S, Ray DD, Vanlahmuaka Das G, Singh NK, Sharma JK, Azhahianambi P (2008). Progress in development of vaccine against Hyalomma anatolicum anatolicum - Indian scenario. Vaccine. 26S: G40-G47. http://dx.doi.org/10.1016/j. vaccine.2008.09.067

- Graf JF, Gogolewski R, Leach-Bing N, Sabatini GA, Molento MB, Bordine L, Arantes GJ (2004). Tick control: An industry point of view. Parasitology. 129: 427-442. http:// dx.doi.org/10.1017/S0031182004006079

- Gupta AK (1984). Role of public enterprises in backward regions generating peasants' perspectives? Working Paper Number 511, Indian Institute of Management, Ahmedabad.

- Gupta AK (1995). Survival under stress: Socioecological perspectives on farmers' innovations and risk adjustments. In. Warren M., Slikkerveer, L.J. and Borkensha, D (Eds). The cultural dimension of development, Intermediate Technology Publications Ltd., London. Pp. 407-418. http:// dx.doi.org/10.3362/9781780444734.032

- Holmes PH (1997). New approaches to the integrated control of typanosomiasis. Vet. Parasitol. 71: 121-135. http://dx.doi. org/10.1016/S0304-4017(97)00026-5

-Itty P, Swallow BM, Rowlands GJ, Mulatu W, d'Ieteren GDM (1995).The economics of village cattle production in a tsetse-infested area of southwest Ethiopia. Prevent. Vet. Med. 22 (3): 183-196. http://dx.doi.org/10.1016/01675877(94)00409-C

-Jonsson NN, Hope M (2007). Progress in the epidemiology and diagnosis of amitraz resistance in the cattle tick Boophilus microplus- A review, Vet. Parasitol. 146: 193-198. http:// dx.doi.org/10.1016/j.vetpar.2007.03.006

- Jongejan F, Uilenberg G (1994). Ticks and Control methods. Revue scientifiqueet technique (International Office of Epizootics). 13(4): 1201-1226.

-Kadivendi M, Maheswari R, Ravikumar RK, Chauhan MM, Kinhekar AS, Kumar V, Kumar V (2015). Integrated Approach for Engaging Farming Community Opportunities and Challenges for Low Cost Inputs. 3(6): 1691-1695.

- Kerlingner FN (2004). Foundations of Behavioural Research. $2^{\text {nd }}$ edition, Surjeet publications. New Delhi Pp. 395.

-Kiss T, Cadar D, Spinu M (2012). Tick prevention at a crossroad: New and renewed solutions. Vet. parasitol.187: 357-366. http://dx.doi.org/10.1016/j.vetpar.2012.02.010

-Klafke, GM, Sabatini GA, de Albuquerque TA, Martins JR, Kemp DH, Miller RJ, Schemaker TS (2006). Larval immersion tests with ivermectin in populations of the cattle tick Rhipicephalus (Boophilus) microplus (acari: Ixodidae) from State of Sao Paulo, Brazil. Vet. Parasitol.142: 386-390. http://dx.doi.org/10.1016/j.vetpar.2006.07.001

- Kumar S, Paul S, Sharma AK, Kumar R, Tewari SS, Chaudhuri P, Ray DD, Rawat AKS, Ghosh S (2011). Diazinon resistant status in Rhipicephalus (Boophilus) microplus collected from different agro-climatic regions of India. Vet. Parasitol. 181: 274-281. http://dx.doi.org/10.1016/j.vetpar.2011.04.030

-Machila N, Emongor R, Shaw AP, Welburn SC, McDermott J, Maudlin I, Eisler MC (2007). A community education intervention to improve bovine trypanosomiasis knowledge and appropriate use of trypanocidal drugs on small holder farms in Kenya. Agri. Syst. 94: 261-272. http://dx.doi. org/10.1016/j.agsy.2006.09.004

- Maciel MV, Morais SM, BevilaquaCML, Camurc, aVasconcelosALF, Costa CTC, Castro CMS (2006). Ovicidal and larvicidal activity of Melia azedarach extracts on Haemonchus contortus. Vet. Parasitol. 140: 98-104. http:// dx.doi.org/10.1016/j.vetpar.2006.03.007

-Maiti S, Chakravarty P, Garai S, Bandyopadhyay S, Chouhan, VS (2013). Ethno-veterinary practices for ephemeral fever of Yak: A participatory assessment by the Monpa tribe of Arunachal Pradesh. Indian J. Trad. Knowledge. 12 (1): 3639.

-Mcdermott JJ, Randolph TF, Staal SJ (1999). The economics of optimal health and productivity in smallholder livestock systems in developing countries, Revuescientifiqueet technique (International Office of Epizootics). 18 (2): 399424.

-Mendes MC, Lima CKP, Nogueira AHC, Yoshihara E, Chiebao DP, Gabriel FHL, Ueno TEH, Namindome A, Klafke GM (2011). Resistance to cypermethrin, deltamethrin and chlorpyriphos in populations of Rhipicephalus (Boophilus) microplus (Acari: Ixodidae) from small farms of the State of São Paulo, Brazil. Vet. Parasitol. 178: 383-388. http://dx.doi. org/10.1016/j.vetpar.2011.01.006

-Minjauw B, Mcleod A (2003). Tick borne diseases and poverty, the impact of ticks and tick borne diseases on the livelihood of small scale and marginal livestock owners in India and eastern and southern Africa. Research report, DFID Animal Health Programme, Centre for Tropical Veterinary Medicine, University of Edinburg, UK.

-Mondal DB, Sarma K, Saravanan M (2013). Upcoming of the integrated tick control program of ruminants with special emphasis on livestock farming system in India. Ticks Tick Borne Dis. 4:1-10. http://dx.doi.org/10.1016/j. ttbdis.2012.05.006

-Mort M, Convery I, Baxter J, Bailey C (2005). Psychosocial effects of the $2001 \mathrm{UK}$ foot and mouth disease epidemic in a rural population: qualitative diary based study. Brit. Med. J. 331(7527): 1234. http://dx.doi.org/10.1136/ bmj.38603.375856.68

- Odendaal JSJ (1998). The practicing veterinarian and animal welfare as a human endeavour. Appl. Anim. Behav. Sci. 59: 85-91. http://dx.doi.org/10.1016/S0168-1591(98)00123-3

-Patel JB, Patel S, Patel P, Ravikumar RK, Kinhekar AS, Kumar V, Ingle VC Awandkar S, Temburne PA, Kumar V (2015). Poultry immunity against Ranikhet Disease Virus (RDV)A Case study of an indigenous poultry medication in village production systems of Maharashtra, India. J. Chem. Pharm. Res. 7(4): 1040-1042.

-Periyaveeturaman C, Selvaraju D, Kinhekar AS, Singh 
PK, Ravikumar RK, Kumar V (2015). Effiacy of herbal composition against ectoparasite infestation in dogs. Adv. Appl. Sci. Res. 6(8): 242-245.

-Prakasan K, Ramani N (2007). Tick parasites of domestic animals of Kerala, South India. Asian J. Anim. Vet. Adv. 2(2): 74-80. http://dx.doi.org/10.3923/ajava.2007.74.80

-Pretty J (2008). Agricultural sustainability: Concepts, principles and evidence. Phil. Trans. R. Soc. B. 363: 447-465. http:// dx.doi.org/10.3763/ijas.2007.0322

-Pretty JN, Morison JIL, Hine RE (2003). Reducing food poverty by increasing agriculturalsustainability in developing countries. Agri. Ecosyst. Environ. 95: 217-234. http://dx.doi. org/10.1016/S0167-8809(02)00087-7

- Perry BD, Mwanaumo B, Schels HF, Eicher E, Zaman MR (1984). A study of health and productivity of traditionally managed cattle in Zambia. Prevent. Vet. Med. 2(5): 633-653. http://dx.doi.org/10.1016/0167-5877(84)90011-4

- Prasad CS (2005). Science and Technology in civil society Innovation trajectory of spirulina algal technology. Economic and Political weekly. Oct. 4363-4372.

- Radostits OM, Gay CC, Blood DC, Hinchcliff KW (2000). Veterinary medicine: a textbook of the diseases of cattle, sheep, pigs, goats and Horses. Ninth edition, W B Saunders company ltd., London.

- Rajput ZI, Hu S H, Chen WJ, Arijo AG, Xiao CW (2006). Importance of ticks and their chemical and immunological control in livestock. J. Zhejiang Uni. Sci. B. 7(11): 912-921. http://dx.doi.org/10.1631/jzus.2006.B0912

- Ravikumar RK, Kumar V, Choudhary H, Kinhekar AS, Kumar $V(2015)$. Efficacy of indigenous polyherbal ectoparasiticide formulation against hard tick infestation in cattle (Bos indicus). Ruminant Sci. 4(1): 43-47.

- Ravikumar RK, ChoudharyH,Kumar V (2015a). Means for retaining farming communities in semi-arid regions of Gujarat state. Agri. Update. 10(2): 158-163. http://dx.doi. org/10.15740/HAS/AU/10.2/158-163

- Ravikumar RK, Dutta L, Kumar V, Kumar V (2015b). Strengthening indigenous veterinary system- An approach for mobilizing community from West Bengal. Asian Acad. Res. J. Social Sci. Human. 1(34):286-290.

- Ravikumar RK, Chander M (2011). Livestock extension education activities of the State Departments of Animal Husbandry (SDAH) in India: A case of Tamil Nadu State. Indian J. Anim. Sci. 81(7): 757-762.

- Ravikumar RK, Rao S, Bose SC,Sudhakar K (2004). Validity of ethnoveterinary practices adopted by farmers in Dindigul district of Tamil Nadu. Asian Agri-History. 8 (1): 55-61.

- Regassa A (2000). The use of herbal preparations for tick control in Western Ethiopia. J. South Africa. Vet. Assoc. 71(4): 240243. http://dx.doi.org/10.4102/jsava.v71i4.722

- Rich KM, Perry BD (2011). The economic and poverty impacts of animal diseases in developing countries: New roles, new demands for economics and epidemiology, Prevent. Vet. Med. 101: 133- 147. http://dx.doi.org/10.1016/j. prevetmed.2010.08.002

- Rodriguez-Vivas RI, Treesb AJ, Rosado-Aguilar JA, VillegasPerez SL, Hodgkinson JE (2011). Evolution of acaricide resistance: Phenotypic and genotypic changes in field populations of Rhipicephalus (Boophilus) microplus in response to pyrethroid selection pressure. Int. J. Parasitol. 41: 895-903. http://dx.doi.org/10.1016/j.ijpara.2011.03.012

-Roling N (1988). Extension science: Information systems in Agricultural Development, Cambridge University Press,

\section{Cambridge. Pp. 1-18.}

- Sharma AK, Kumar R, Kumar S, Nagar G, Singh NK, Rawat SS, Dhakad ML, Rawat AKS, Ray DD, Ghosh, S (2012). Deltamethrin and cypermethrin resistance status of Rhipicephalus (Boophilus) microplus collected from six agro climatic regions of India. Vet. Parasitol. 188: 337-345. http:// dx.doi.org/10.1016/j.vetpar.2012.03.050

-Siegel S, Castellan NJ (1988). Nonparametric statistics for the behavioural sciences, Second edition, McGraw-Hill International editions, Singapore.

-Subedi A, Garforth C (1996). Gender, information and communication networks: Implications for extension. Europ. J. Agri. Educat. Exten. 3(2): 63-74. http://dx.doi. org/10.1080/13892249685300201

-Swallow BM, Mulatu W, Leak SGA (1995). Potential demand for a mixed public-private animal health input: evaluation of a pour-on insecticide for controlling tsetse-transmitted trypanosomiasis in Ethiopia. Prevent. Vet. Med. 24: 265275. http://dx.doi.org/10.1016/0167-5877(95)00486-G

-Tambi NE, Mukhebi WA, Maina WO, Solomon HM (1999). Probit analysis of livestock producers' demand for private veterinary services in the high potential areas of Kenya. Agri. Syst. 59: 163-176. http://dx.doi.org/10.1016/S0308521X(98)00088-2

-Terrill TH, Miller JE, Burke JM, Mosjidis JA, Kaplan RM (2012). Experiences with integrated concepts for the control of Haemonchus contortus in sheep and goats in the United States. Vet. Parasitol. 186: 28-37. http://dx.doi. org/10.1016/j.vetpar.2011.11.043

-Turkson PK, Naandam J (2003). Assessment of veterinary needs of ruminant livestock owners in Ghana. Prevent. Vet. Med. 61: 185-194. http://dx.doi.org/10.1016/j. prevetmed.2003.07.005

-UNEP (2008). Organic Agriculture and Food Security in Africa. United Nations Environment Programme-United Nations Conference on Trade and Development (UNEPUNCTAD) Capacity building Task Force on Trade, Environment and Development, United Nations, New York and Geneva. http://unctad.org/en/docs/ditcted200715 en.pdf

- Vandermerwe JS, Smit FJ, Durand AM, Krüger LP, Michael LM (2005). Acaricide efficiency of amitraz/cypermethrin and abamectin pour-on preparations in game. Onderstepoort J. Vet. Res. 72: 309-314.

-Whalon ME, Mota-Sanchez D, Hollingworth RM (2008). Global pesticide resistance in Arthropods. CAB International, Oxfordshhire, UK. Pp. 18. http://dx.doi. org/10.1079/9781845933531.0000

-Wood S, Sebastien K, Scherr SJ (2000). Pilot analysis of global ecosystems. International Food Policy Research Institute (IFPRI) and World Resources Institute (WRI), Washington D.C. http://www.wri.org/sites/default/files/pdf/page_ agroecosystems.pdf 